\title{
Chance to make a difference in Japan
}

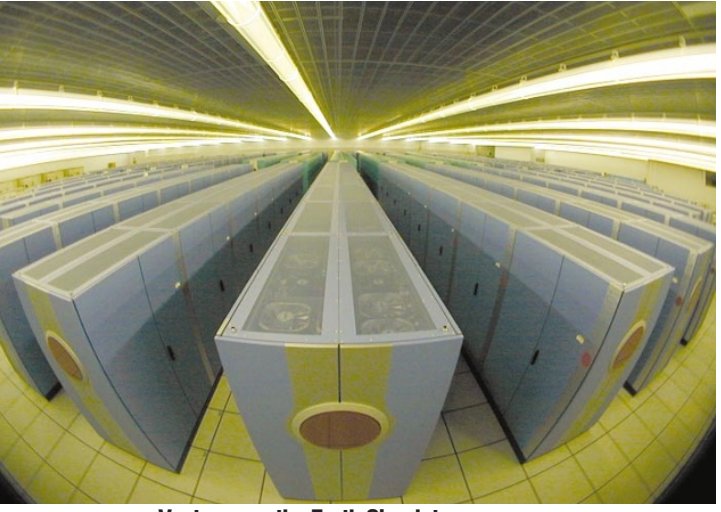

Vast power: the Earth Simulator.

$n$ the early years after the Second World War, young meteorologists in Japan had little choice but to go abroad; positions were few, equipment primitive and funding scant. During the 1950s and 1960s, many went to work in the United States. Syukuro Manabe, a pioneer in climate modelling and research on global climate change, was one of them.

His return in 1997 may be a sign that things are changing. Although investment in human resources and software development lags behind spending on infrastructure, the amount poured into computational facilities is proving a draw. It may even solve other underinvestment problems, by attracting the best and the brightest to Japan to work in fields such as climate-model development.

Manabe returned to head the Global Warming Research Program at the newly established Frontier Research System for Global Change. Its facilities on the outskirts of Yokohama are an integral part of a longterm strategy for research into regional and global climate change promoted by the Japanese government.

Another part of Japan's climate-research strategy is the Earth Simulator, a computer system dedicated to research in the geosciences (see Nature 416, 579-580; 2002) at least an order of magnitude more powerful than any other system available to climate scientists.

\section{DEVELOPING HUMAN RESOURCES}

Both facilities have had some investment in human resources. As well as encouraging international links (see 'An international angle', right), the Frontier system offers 160 limited-term positions - just enough to absorb a stream of new graduates coming out of newly established $\mathrm{PhD}$ programmes at large national universities, points out Toshio Yamagata, a professor in the department of Earth and planetary science at the University of Tokyo.

But although the Frontier system and other priority funding schemes — such as the CREST (Core Research for Evolutional Science and Technology) programme administered by the Japan Science and Technology Corporation - are providing new positions and muchneeded research money, some argue that a longer-term research strategy is needed. According to Tetsuzo Yasunari, a professor in the department of Earth sciences at Tsukuba University, one important issue for climate research in Japan is the shortage of human resources.

Limited senior-research capacity means that most director positions at the Frontier system have been filled by university professors on joint appointments. Also, says Yasunari, although limited-term positions have surged as a result of the Frontier programme, there has been hardly any change in the number of tenured faculty positions. In Japan's inflexible labour market, this means that many young scientists will find themselves without work once their Frontier contracts expire - and, like several decades ago, they will have little option other than to go abroad.

Although some areas of geoscience - notably earthquake research and volcanology - have received generous funding for over 30 years, the movement of cash into climate research has been relatively recent. Other disciplines, such as palaeontology and geology, have seen hardly any increase in funds in recent years. "We have clearly been lucky," says Yasunari. "Now we need to demonstrate that the funding increases were justified."

Robert Triendl is is a freelance writer based in Tokyo.

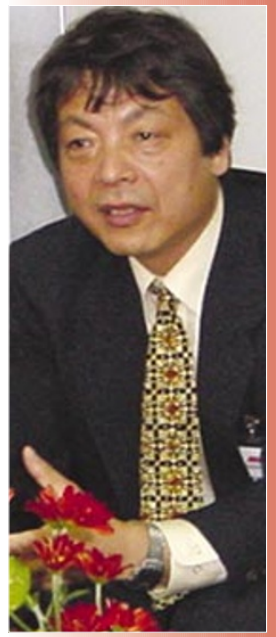

Tetsuzo Yasunari is eager to prove that funding was justified. 